\title{
On the Finite-Element Analysis of Resonance MEMS Structures based on Acoustic Lamb Waves
}

\author{
Pavel S. Marinushkin, Alexey A. Levitsky, Fyodor G. Zograf, Valentina A. Bakhtina \\ Siberian Federal University, School of Engineering Physics and Radio Electronics, Krasnoyarsk, Russia
}

\begin{abstract}
This paper considers issues of modeling ultra-high frequency MEMS resonators based on acoustic Lamb waves. In addition, the analysis of factors that determine whether it is possible to increase resonators working frequency and electromechanical coupling factor is carried out. Influence of resonator excitation scheme and acoustic waveguide thickness for a range of piezoelectric materials (i.e. AlN, ZnO, GaN) on phase velocity for acoustic Lamb wave zero modes is investigated. As a result, we've got estimations determining dependence of resonators electromechanical coupling coefficient on their geometry.
\end{abstract}

\section{Analiza končnih elementov resonance MEMS struktur za akustične Lamb valove}

Izvleček: Članek opisuje problem modeliranja ultra visokih frekvenc MEMS resonatorjev za akustične Lamb valove. Dodatno je bila opravljena analiza faktorjev, ki določajo možnost povečanja delovne frekvence resonatorja in faktor elektromehaničnega sklopljenja. Raziskan je vpliv vzbujalne sheme resonatorja in debeline akustičnega vodnika za različne piezoelektrične materiale (npr. AIN, $\mathrm{ZnO}, \mathrm{GaN}$ ) na fazno hitrost akustičnih Lamb valov v ničelnem modu. Kot rezultat podajamo oceno odvisnosti elektromehanične sklopljenosti resonatorja od njegove geometrije.

Ključne besede: akustični valovi; metoda končnih elementov; mikro elektromehanični element (MEMS); piezoelektrične plasti; mikrovalovni resonator

*Corresponding Author's e-mail: marinushkin_ps@mail.ru

\section{Introduction}

The growing demand for developing modern space telecommunication devices and constructing new prospective ones, radar and radio navigation systems condition the necessity of substantial working frequency increase of frequency-selective devices. Due to the mentioned above reasons, in recent years most researches have been focused on developing microelectromechanical (MEMS) resonators that have a rather small size, high quality factor values, active device integration function, good resistance to impact and vibration loads and possess many other advantages over the rest of the devices with similar functions $[1,2]$.

Increase of MEMS resonators working frequencies based on the widely used constructive options in- volves significant challenges. For instance, resonators based on elements with flexural oscillations reach their scaling limits at frequencies of hundreds of megahertz. It happens because the size needed for higher frequencies is difficult to implement. Moreover, with size decrease the dynamic impedance of such resonators increases, which impedes interfacing with highfrequency devices.

The most prominent way to overcome these limits are resonance structures with contour modes [3-8] that allow implementing micro-resonators with high natural frequencies while dynamic resistance is relatively low, which facilitates the process of matching with RF frontend. 
In this resonator type Lamb waves are used as a working acoustic wave. They propagate in thin mechanically isolated piezoelectric film (the thickness does not exceed acoustic wave length) of anisotropic crystals with hexagonal wurtzite-like structure. In particular, these include films of aluminum nitride (AIN), zinc oxide $(\mathrm{ZnO})$ and gallium nitride ( $\mathrm{GaN})$ that have piezoelectric response along polar axis $C$, i.e. perpendicular to the substrate surface (in 0001 direction). Use of piezoeffect provides opportunity to adjust frequency with constant voltage, while single crystal structure and high rigidity provide potentially high quality factor.

One of the main problems in development of MEMS resonators based on Lamb waves in frequency range of gigahertz units is provision of acceptable efficiency of acoustical transformation with working frequency increase.

The aim of this work is to analyze factors that determine possibility of working frequency increase in UHF MEMS resonators based on Lamb waves and to acquire estimations determining dependence of resonators electromechanical coupling coefficient on their geometry.

\section{Structural and technological implementation of resonators with contour modes}

Development of resonators with contour modes involves use of structures with suspended piezoelectric acoustic waveguide. On its surface metal electrodes are formed and constitute interdigital transducers - IDT. You may find an example of micro-resonator structure at Fig. 1.

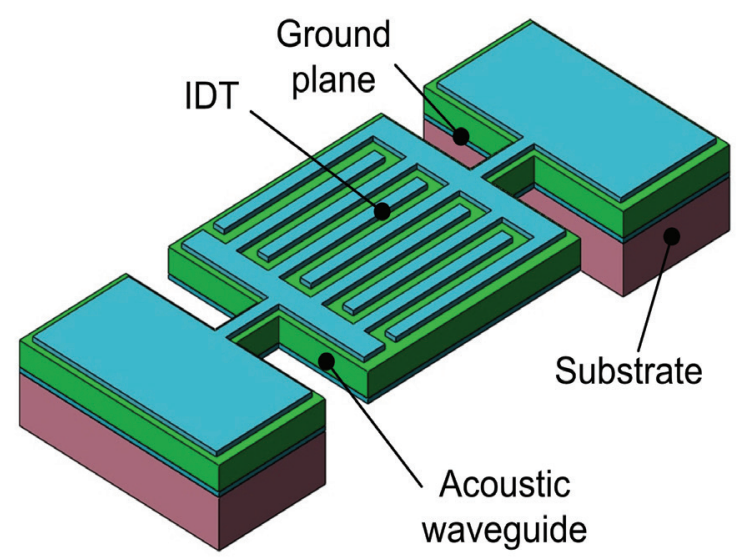

Figure 1: Structure of MEMS resonator with contour oscillations.

Use of a suspended structure with free upper and lower boundaries provides an opportunity to excite Lamb waves within an acoustic waveguide featured by vibrational particle displacement in both wave propagation direction (along the acoustic waveguide) and perpendicular to a plate plane.

Change in length, width and position of the electrodes on acoustic waveguide surface allows to set the necessary frequency resonator's properties. Based on electrodes position we can distinguish a range of basic electrode structures implied in single-input (two-pole) resonators with contour modes (Fig. 2) that implement

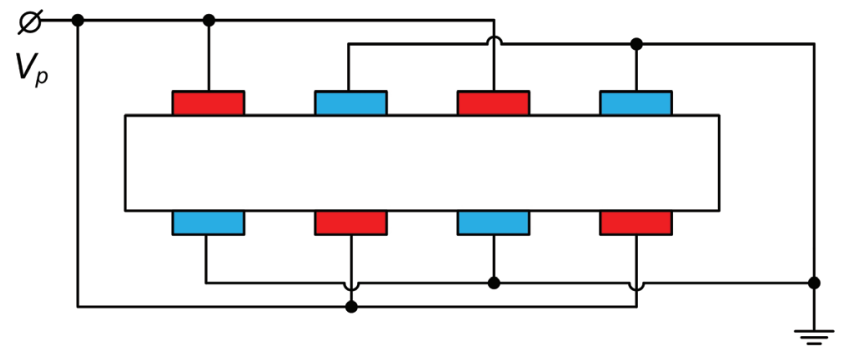

a

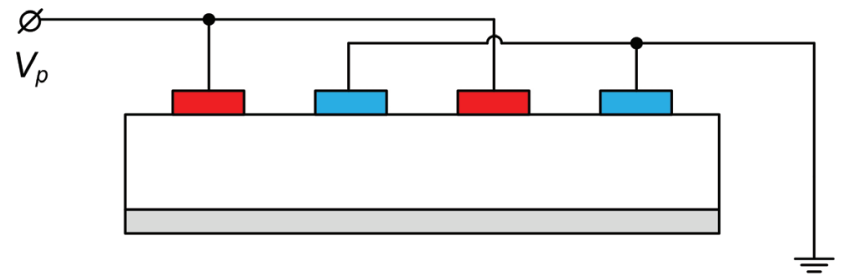

C

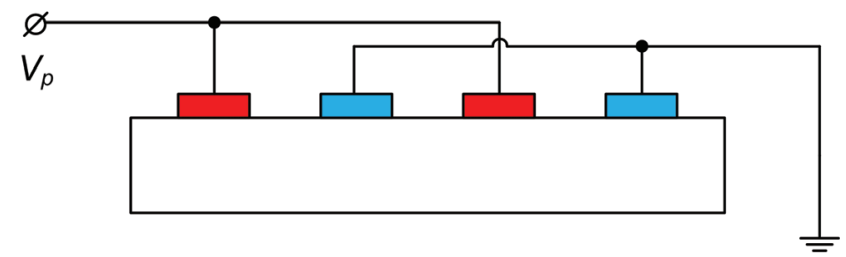

$b$

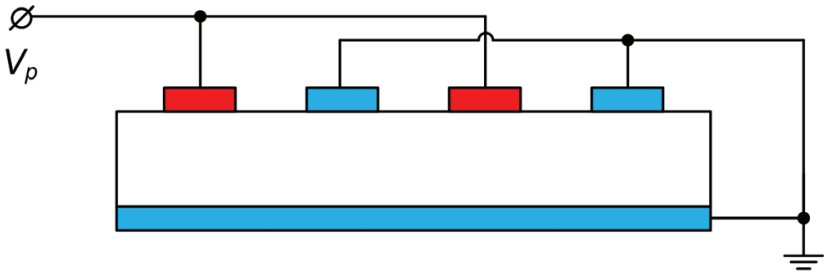

$d$

Figure 2: Options of electrodes position in single-input resonators: $a$ - double IDT, $b$ - single IDT, $c$ - IDT with floating bottom electrode, $d$ - IDT with grounded bottom electrode. 
thickness field excitation (TFE) and lateral field excitation (LFE) (Fig. 2, $a$ and Fig.2, $b-d$ accordingly).

In order to carry out a comparative assessment of micro-resonators we applied a product of working frequency $f$ and quality factor $Q$, i.e. an accessory parameter $f \cdot Q$ [9]. Fig. 3 shows current results achieved for this parameter. You might notice that working frequencies of MEMS resonators with contour modes may reach the value of $10 \mathrm{GHz}$. Feasibility of further working frequency increase is limited by the resolution of photolithographic process.

In practice, resonators with contour modes have internal quality characteristic values that do not exceed hundreds of gigahertz. With frequency increase, quality factor usually decreases. The fundamental limit of quality factor increases results in viscous losses in materials, side leakage of acoustic energy and dissipation at microroughness [9-11]. Despite these facts, there is still a way to develop MEMS resonators based on Lamb waves with quality factor of $\sim 5000$, applying a special design. To reach this goal a piezoactive layer equipped with IDT should be placed on the acoustic transmission line made of high-quality materials: sapphire [12], silicon carbide SiC [13]. Resonators constructed with the help of this technology are called composite acoustic resonators LOBAR (Lateral Overtone Bulk Acoustic Resonators). Use of a mixed capacitive-piezoelectric conversion mechanism allows implementing resonators with quality factor value over $10^{4}$ [14].

\section{Model of wave processes in MEMS resonators based on Lamb waves}

Forming a resonator model implies accepting a list of assumptions. Firstly, it is useful to consider only the coupled elasticity theory and piezoelectricity problem, leaving aside electromagnetic field's properties, regarding it in quasi-static approximation (in comparison to electromagnetic wavelength the structure's size is rather small). Secondly, it is assumed that oscillation amplitude is small and processes in active layer and electrodes materials are described by linear theories of piezoelectricity and elasticity. Finally, bulk forces that affect resonator and internal loss should be omitted; oscillations occur in vacuum.

We will handle this problem in two-dimensional setting, supposing that resonator has an unlimited work field perpendicular to the considered structure section. To analyze acoustic processes let's look at resonator's part of length $L=\lambda$, that contains two exciting electrodes (Fig. 4). Within each one we will acquire solution for coupled electroelasticity problem with relevant boundary conditions.

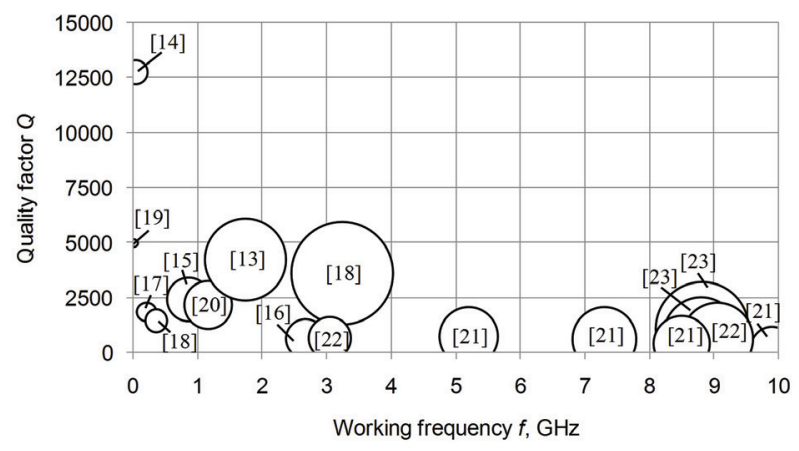

Figure 3: Values $f$ and $Q$ calculated for resonators with contour modes (according to results from [13-23]. Size of „bubbles" reflects resonator's level of quality $f \cdot Q$.

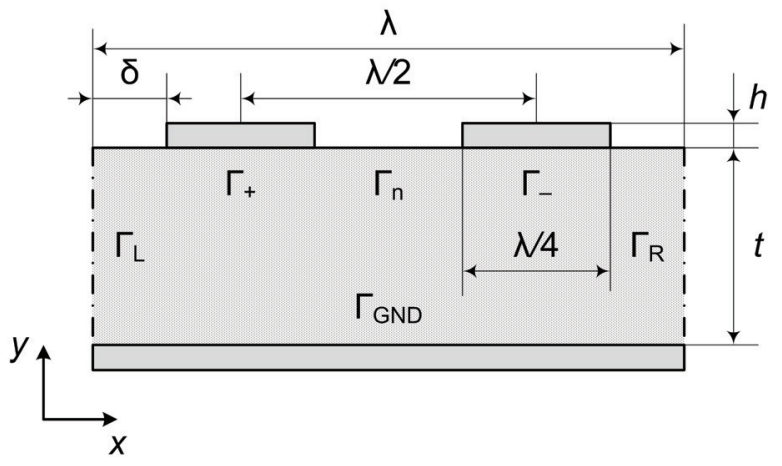

Figure 4: Model of Lamb wave micro-resonator's unit cell corresponding to Fig. 2, $c$ and Fig. 2, $d$.

System of governing equations for piezoelectric materials that couple mechanical stress $\mathbf{T}$ and strain $\mathbf{S}$ to electric field intensity $\mathbf{E}$ and electric displacement $\mathbf{D}$ is as follows [24, 25]:

$$
\begin{aligned}
& \mathbf{T}=\mathbf{c}_{E} \mathbf{S}-\mathbf{e E} \\
& \mathbf{D}=\boldsymbol{\varepsilon}_{\boldsymbol{S}} \mathbf{E}+\mathbf{e}^{T} \mathbf{S},
\end{aligned}
$$

where $\mathbf{c}_{\mathrm{E}}$ is tensor of elasticity coefficients at constant electric field, $\mathbf{e}$ is tensor of piezoelectric constants, $\varepsilon_{\mathrm{s}}$ is tensor of dielectric constants measured in presence of constant strains, $T$ denotes matrix transposition.

Boundary conditions on exciting electrodes surfaces (see Fig.4) constitute Dirichlet condition for electric potential $\varphi$ :

- $\varphi=\varphi_{\mathrm{p}}$ for the sector of the boundary $\Gamma_{+^{\prime}} \varphi=-\varphi_{\mathrm{p}}$ for the sector of the boundary $\Gamma_{\_}$, $\varphi=0$ at grounded bottom metallization $\Gamma_{\mathrm{GND}}$ (Fig. 2, c),

- $\quad \varphi=$ const at bottom metallization with floating potential $\Gamma_{\mathrm{FP}}$ (Fig. 2, $\mathrm{C}$ ). 
Boundary conditions that constitute continuity of normal components of electric displacement vector are set at left and right unit cell boundaries $\left(\Gamma_{L^{\prime}} \Gamma_{R}\right.$ sectors at Fig. 4):

$$
\mathbf{n} \cdot \mathbf{D}_{x=0}=\mathbf{n} \cdot \mathbf{D}_{x=L},
$$

continuity of electric field tangential components:.

$$
V_{x=0}=V_{x=L},
$$

continuity of normal mechanical stresses:

$\mathbf{n} \cdot \mathbf{T}_{x=0}=\mathbf{n} \cdot \mathbf{T}_{x=L}$,

and continuity of mechanical displacements:

$u_{x=0}=u_{x=L}$

For metallization-free sectors of piezoelectric surface, we set Von Neumann boundary conditions that describe lack of currents flowing across the boundary:

$\mathbf{n} \cdot \mathbf{D}=0, \forall N\{x, y\} \in \boldsymbol{\Gamma}_{\mathrm{n}}$,

and Von Neumann condition for normal surface voltage level:

$\mathbf{n} \cdot \mathbf{D}=0, \forall N\{x, y\} \in \boldsymbol{\Gamma}_{+}, \boldsymbol{\Gamma}_{-}, \boldsymbol{\Gamma}_{\mathrm{GND}}, \boldsymbol{\Gamma}_{\mathrm{n}}$,

where $\mathbf{n}$ is a vector of unit external normal to the surface.

Analysis of the wave pattern determining resonance structure processes was carried out to identify types of excited waves and to assess correspondence of model and physical processes flowing in micro-resonators. Determination of micro-resonators natural frequencies and oscillation modes was carried out for structures based on AIN, ZnO and GaN. Parameters of the materials used for calculations are presented in Table 1. Behavior of hexagonal crystals AIN, $\mathrm{ZnO}, \mathrm{GaN}$ is characterized by five independent elastic constants $-C_{11^{\prime}}, C_{12^{\prime}}$
$C_{13^{\prime}} C_{33^{\prime}} C_{44^{\prime}}$ three independent piezoelectric constants $-e_{15^{\prime}}, e_{31}, e_{33}$ and two independent dielectric constants $-\varepsilon_{11}, \varepsilon_{33}$. Three independent elastic constants that are needed to describe cubic crystals Al are $C_{11}, C_{12}, C_{44}$

Calculations were carried out using finite element method (FEM) of ANSYS software package [24,25]. FEM procedures were performed in ANSYS APDL language with the help of two-dimensional finite element PLANE223 with degrees of freedom UX, UY, VOLT. Finite element description acquired in parametric form allows varying model's geometric parameters and materials physical properties, calculating resonators structures with different electrodes position options (see Fig. 2, $a-d)$. As a result of modal analysis, we obtained resonators natural frequencies and corresponding oscillation modes representing the relative amplitudes of displacements at finite-element mesh nodes.

If you look at Fig. 5, you may see first four oscillation modes of resonance structure based on aluminum nitride (the structure with single IDT and a grounded bottom electrode - Fig. $2, d$, the working wavelength $\lambda \approx 4 \mu \mathrm{m}$, thickness of top and bottom Al-electrodes is $0.1 \mu \mathrm{m})$. The figure shows characteristic features of Lamb waves: wave pattern is featured by two components of vibrational displacement, one of which is parallel and the other is perpendicular to the acoustic transmission line surface. Modes, that differ in motion of resonator's top and bottom surfaces in the same and opposite directions, belong to symmetric and asymmetric Lamb modes respectively.

The problem of micro-resonator electrode system topology choice is closely connected to the problem of determination of acoustic waves phase speed in thin piezoelectric's plate at frequencies corresponding to the natural modes.

\begin{tabular}{|c|c|c|c|c|c|}
\hline \multicolumn{2}{|l|}{ Parameter } & AIN & $\mathrm{ZnO}$ & $\mathrm{GaN}$ & $\mathrm{Al}$ \\
\hline \multicolumn{2}{|l|}{ Density, $\mathrm{kg} / \mathrm{m}^{3}$} & 3260 & 5700 & 6150 & 2700 \\
\hline \multicolumn{2}{|l|}{ Poisson ratio } & 0.287 & 0.36 & 0.352 & 0.3 \\
\hline \multirow{6}{*}{$\begin{array}{l}\text { Elastic constants, } \\
\text { GPa }\end{array}$} & $C_{11}$ & 345 & 210 & 390 & 112 \\
\hline & $C_{12}$ & 125 & 121 & 145 & 60 \\
\hline & $\mathrm{C}_{13}$ & 120 & 105 & 106 & - \\
\hline & $C_{33}$ & 395 & 211 & 398 & - \\
\hline & $C_{44}$ & 118 & 43 & 105 & 44 \\
\hline & $\mathrm{C}_{66}$ & 110 & 44.5 & 122.5 & - \\
\hline \multirow{3}{*}{$\begin{array}{l}\text { Piezoelectric } \\
\text { constants, } \mathrm{C} / \mathrm{m}^{2}\end{array}$} & $\mathrm{e}_{15}$ & -0.48 & -0.48 & -0.3 & - \\
\hline & $e_{31}$ & -0.58 & -0.57 & -0.33 & - \\
\hline & $e_{33}$ & 1.55 & 1.32 & 0.65 & - \\
\hline \multirow{2}{*}{\begin{tabular}{|l}
$\begin{array}{l}\text { Relative dielectric } \\
\text { permitivity }\end{array}$ \\
\end{tabular}} & $\varepsilon_{11}$ & 9.04 & 8.6 & 9.5 & - \\
\hline & $\varepsilon_{33}$ & 11.2 & 10 & 10.4 & - \\
\hline
\end{tabular}

Table 1: Parameters of the materials used for calculations $[15,26,27]$. 

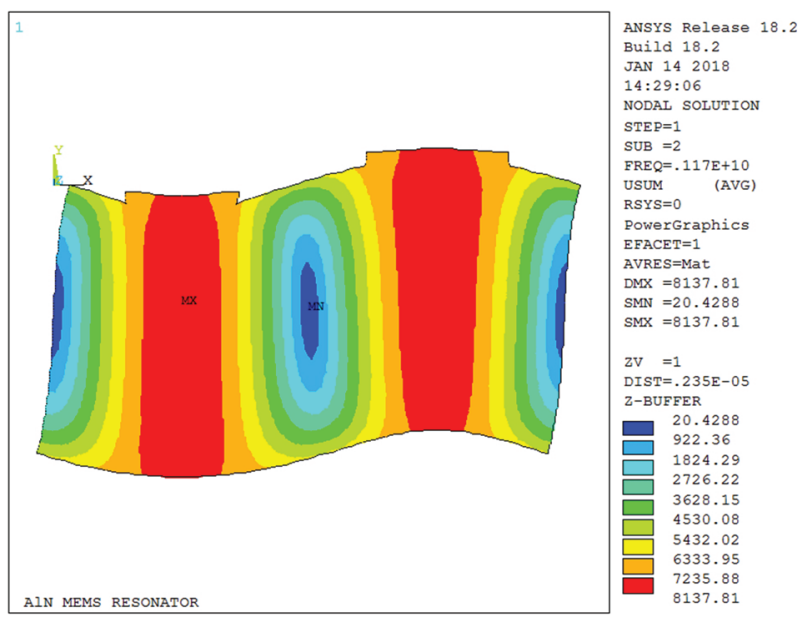

a

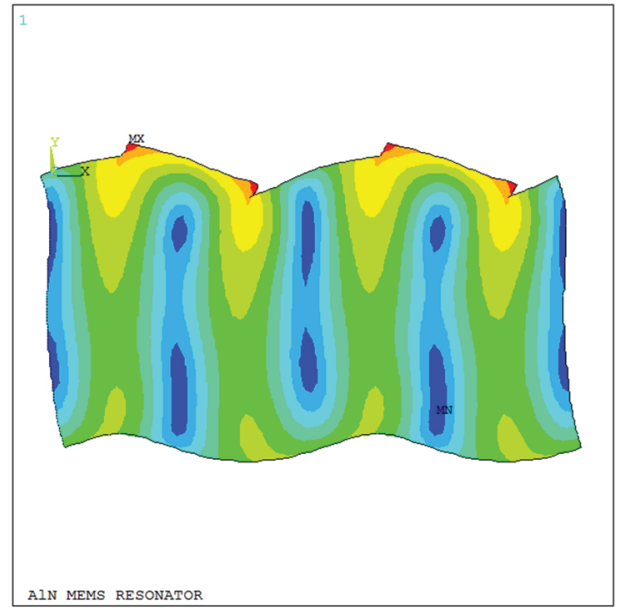

C
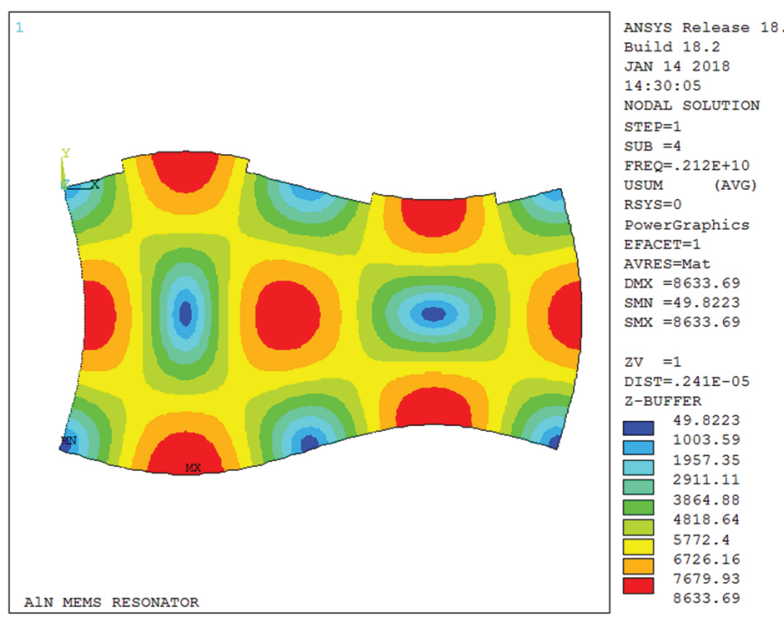

b

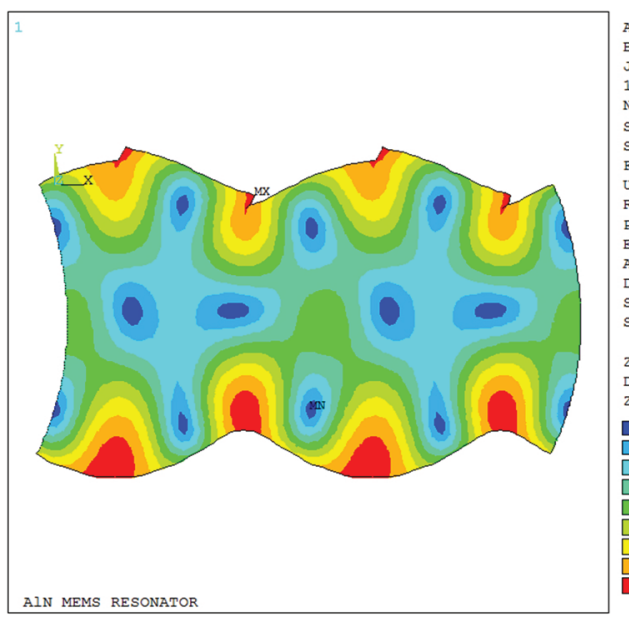

ANSYS Release 18.2 Juild 18.2 $14: 27: 05$ ODAL SOLUTION STEP $=1$ SUB $=14$
FREQ $=.303 \mathrm{E}+10$ REQ $=.303 E+10$ RSYS $=0$ powerGraphics EFACET $=1$ VRE $S=$ Mat $M X=11656.9$ $\mathrm{MN}=32.1505$ $\mathrm{zV}=1$ DIST $=.234 \mathrm{E}-05$
$\mathrm{DIV}$ Z-BUFFER 32.1505
1323.79
2615.43
3907.08 5198.72 5198.72
6490.36 7782 9073.65
10365.3
11656.9

$d$

Figure 5: Lamb modes in the structure based on AIN: $a$ - asymmetric $A_{0}(1.17 \mathrm{GHz}), b$ - symmetric $\mathrm{S}_{0}(2.12 \mathrm{GHz})$, $c$ - asymmetric $\mathrm{A}_{1}(2.64 \mathrm{GHz}), d$ - symmetric $\mathrm{S}_{1}(3.03 \mathrm{GHz})$.

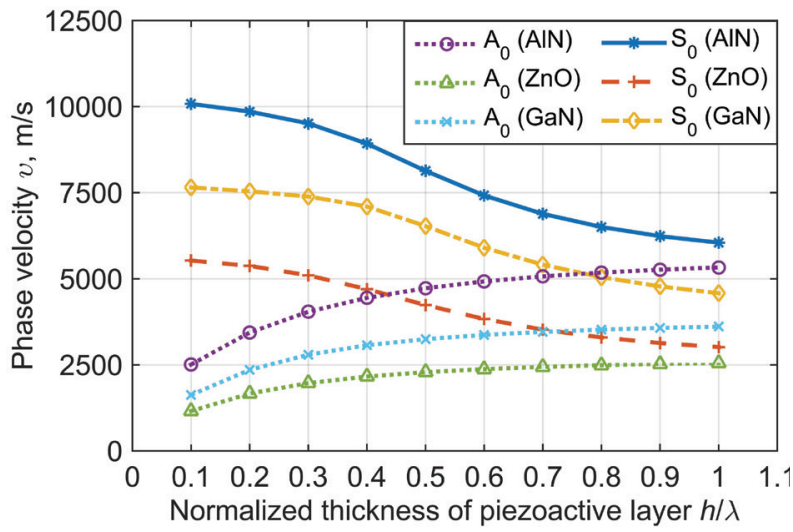

Figure 6: Dependence of Lamb wave propagation phase velocity for zero symmetric mode in film made of AIN, ZnO and GaN with orientation (0001) from their relative thickness (calculations are made for single IDT with grounded bottom electrode, thickness of top and bottom Al-electrodes is $0.1 \mu \mathrm{m}$, variable parameter is acoustic waveguide thickness $t$ ).
The dependence represented in Fig.6 allows determining spatial period $p$ between antiphase excited IDT electrodes from the selected excitation frequency $f$ and the corresponding phase velocity $\mathrm{U}_{0}: p=\mathrm{U}_{0} /(2 f)$.

The results show that zero symmetric Lamb mode $\mathrm{S}_{0}$ has the main practical value in terms of working frequency increase of micro-resonators with contour modes. In case of aluminum nitride use the wave velocity for this mode may reach the value of $10000 \mathrm{~m} / \mathrm{s}$ with small relative thickness of film $-t / \lambda<0.2$. Acoustic wave velocity in structures based on $\mathrm{GaN}$ and $\mathrm{ZnO}$ is much lower, as a result the size of resonators may be extremely small. With the same electrodes spatial period, working frequency of aluminum nitride resonators is 1.3 times higher than working frequency of GaN resonators and almost twice higher than that of $\mathrm{ZnO}$ resonators. 


\section{Calculation of electromechanical coupling coefficients}

One of the main issues during development of resonator elements with high $f \cdot Q$ is provision of efficient transformation of electric signals into acoustic ones and vice versa. Aside from piezoelectric properties of material's active layer it is also determined by IDT configuration, electrodes thickness and piezoelectric film ratio, and other design parameters. The best combination of these connected parameters can be obtained by taking an electromechanical coupling effective coefficient as an optimization criterion.

The value of the effective coupling coefficient can be set by calculating frequencies of (resonance) pole and (antiresonance) zero of input micro-resonator's admittance $[4,28]$ :

$$
k_{\mathrm{eff}}^{2}=\frac{\pi^{2}}{4} \frac{f_{\mathrm{s}}}{f_{\mathrm{p}}} \frac{f_{\mathrm{p}}-f_{\mathrm{s}}}{f_{\mathrm{p}}},
$$

where $f_{s}$ and $f_{p}$ are series and parallel resonance frequencies respectively.

Frequencies $f_{s}$ and $f_{p}$ can be found using the harmonic analysis procedure, allowing to determine steady vibrations - resonator's response to the electric harmonic action applied to it with given amplitude and frequency. To acquire frequency dependence of resonator's admittance $Y(f)$ we calculated the values of $Y$ for a given frequency from the charges induced on electrodes (or current flowing through electrodes) found on the basis of a modal analysis and corresponding electric potential.

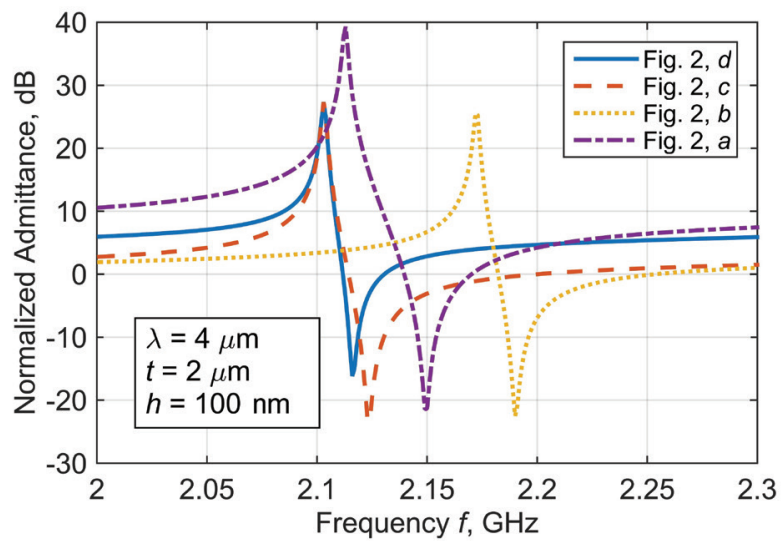

Figure 7: Frequency dependences of conductivity module (normalized to conductivity unit) of a single input AIN-resonator designed for center frequency of $2.72 \mathrm{GHz}$ for different electrode location options. Thickness of top and bottom Al-electrodes is $0.1 \mu \mathrm{m}$, thickness of piezoelectric layer AIN is $2 \mu \mathrm{m}$. $\xi=0.0005$.
During computational experiments in the ANSYS package, value of damping parameter $\xi$ (using DMPRAT command) was set based on theoretical limit value of resonator's quality factor $Q_{m}$ determined by mechanical quality factor of acoustic transmission line material (1500-2500 for aluminum nitride and 1000 for zinc oxide and gallium nitride):

$\xi=\frac{1}{2 \mathrm{Qm}}$,

At the charts (Fig. 7) obtained after modelling you may see that conductivity module frequency dependences $|Y(f)|$ pass through a minimum at preliminary resonance frequency $f_{s}$ and pass through maximum at parallel resonance $f_{\mathrm{p}}$.

Figures 8 shows dependencies $k_{\text {eff }}^{2}$ calculated in accordance with (7) for symmetric mode $S_{0}$ in films of (0001) AIN, ZnO and GaN from relative thickness of piezoactive layer $t / \lambda$ for different electrode location options (Fig.2).

\section{Results}

As follows from the results, electrode structure with double IDT (Fig. 2, a) has the highest acoustical transformation efficiency and single IDT with grounded bottom electrode (Fig. 2, d) has the lowest acoustical transformation efficiency. In aluminum nitride film (Fig. 8) electromechanical coupling coefficient for mode $\mathrm{S}_{0}$ in resonators with double IDT reaches its maximum at film relative thickness of $t / \lambda \approx 0.4$ and has a value $\sim 5 \%$. As you may see at Fig. 8 , in the structure based on zinc oxide coupling coefficient may be higher $(\sim 11.5 \%$ at $t / \lambda \approx 0.3)$.For $\mathrm{GaN}$ the coupling coefficient is the lowest $(\sim 1 \%$ at $t / \lambda \approx 0.4)$.

\section{Discussion}

As calculations demonstrated, double IDT (Fig. 2, a) provides the highest electromechanical coupling coefficient value and maximum distance between adjacent resonant frequencies. The increase in coupling coefficient can be attributed to the better match of the working mode shape to the electrode placement inherent in this design. Besides the higher excitation efficiency, double IDT provides significantly lower level of extraneous waves excitation (Fig. 9). Excitation of extraneous oscillations along with working mode leads to resonator's quality factor decrease. At $t / \lambda=0.5$ working oscillation mode $\mathrm{S}_{0}$ is excited above all, while the rest of modes are largely suppressed (for double IDT). 

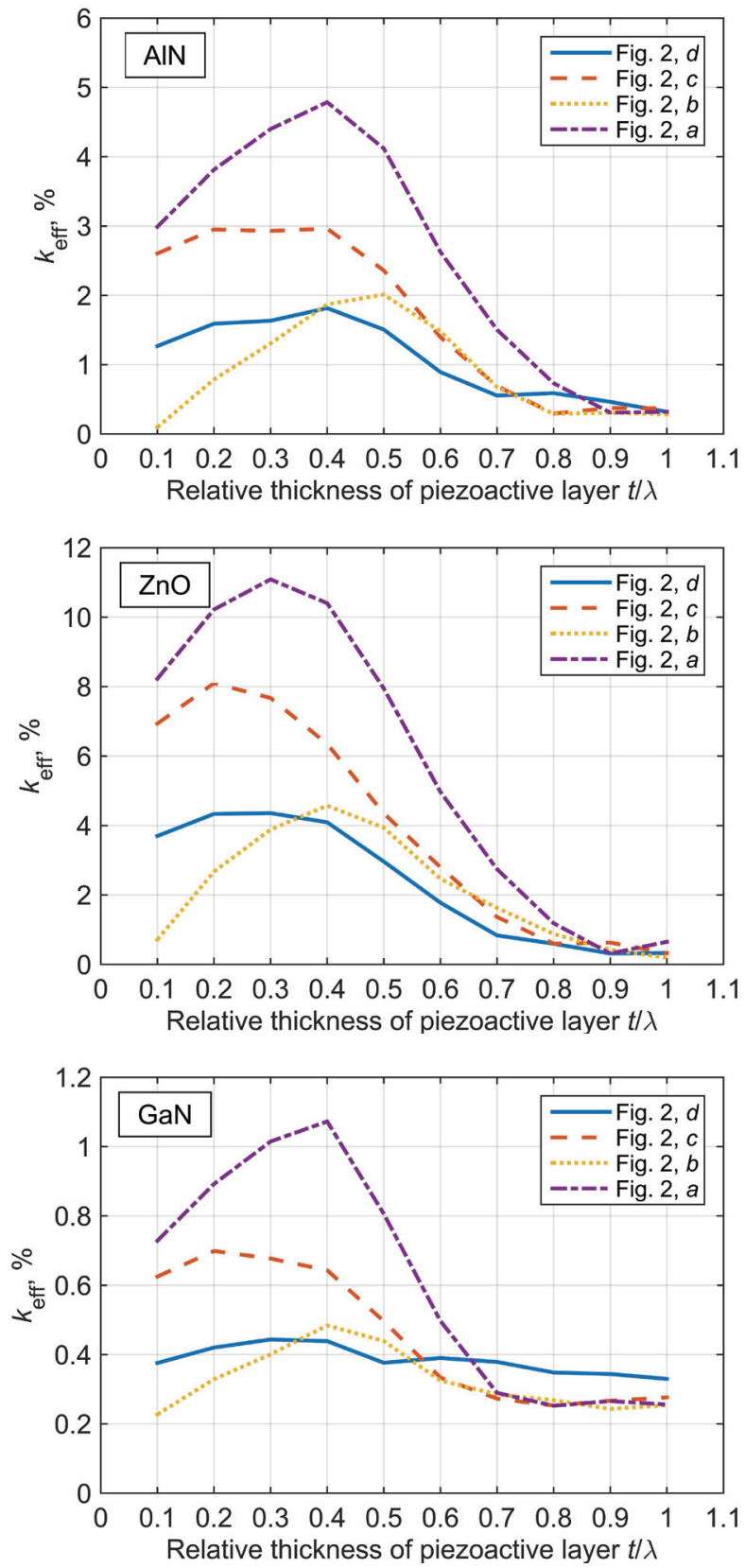

Figure 8: Dependence of electromechanical coupling coefficient value for zero symmetric Lamb mode $\mathrm{S}_{0}$ from piezoactive layer thickness referred to working wavelength $\lambda \approx 4 \mu \mathrm{m}$ for different acoustic transmission line materials.

At the same time, construction of double IDT resonators is troubled by difficulties associated with technological process, i.e. difficulties of high-quality piezoelectric film growing and inaccuracies in top and bottom photolithographic templates combination.

Single IDT resonators stand out for the simplest technology that requires minimum photomasks and, as a result, less manufacturing phases. Therefore, at frequencies higher than $1 \mathrm{GHz}$, where growing piezo- electric layer quality requirements obstruct double IDT structures implementation, it is more appropriate to implement single IDT.

\section{Conclusions}

According to the results, we may determine the main constructive solutions that allow to create single input MEMS resonators based on Lamb waves with suspended structure at gigahertz wavelength range.

Results of numerical analysis show that double IDT resonators, which electrodes are placed at the top and the bottom of suspended piezoelectric layer, allow reaching higher electromechanical coupling factor values in comparison to single IDT options. Implementation of double IDT structures is more complex than implementation of single IDT ones.

As working frequencies increase and restriction of requirements for combination accuracy and technology resolution while micro-resonators manufacturing, it seems more appropriate to use single IDT structures. Resonator's working frequencies may be increased by 5-10 GHz using higher modes.

\section{Acknowledgments}

The authors thank Filipp A. Baron for critical reading of manuscript, fruitful discussions and valuable input.

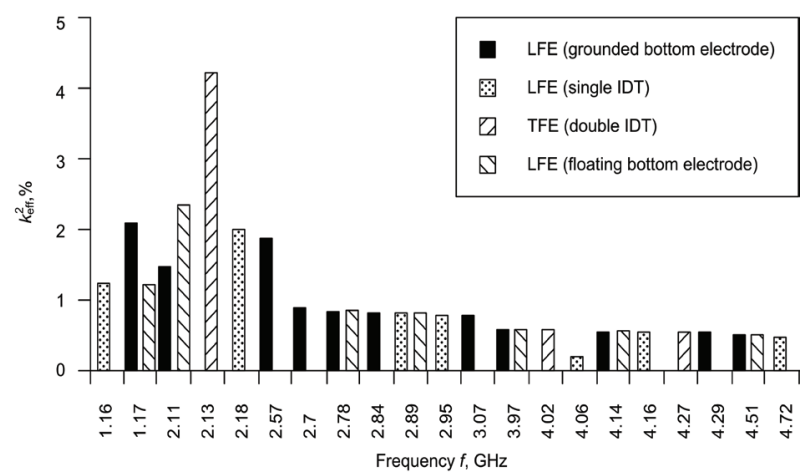

Figure 9: Histogram of the $k_{\text {eff }}^{2}$ dependency from frequency for different resonator excitation circuits (Fig. 2). Acoustic transmission line material is aluminum nitride, $t / \lambda=0.5$. Each histogram column's height represents a value of coupling coefficient at corresponding natural frequency. 


\section{Conflict of interest}

The authors declare no conflicts of interests.

\section{References}

1. J.Basu, T. K. Bhattacharyya, "Microelectromechanical Resonators for Radio Frequency Communication Applications," Microsyst. Technol., vol. 17, no. 10-11, pp. 1557-1580, 2011. https://doi.org/10.1007/s00542-011-1332-9.

2. A. A. Levitskiy, P. S. Marinushkin, "Design and Research of the Micromechanical Resonator," Izvestiya vuz. Fizika, vol. 56, no. 8-3, pp. 159-161, 2013. (in Russian).

3. Y. Hou, M. Zhang, G. Han, C. Si, Y. Zhao, J. Ning, "A review: Aluminum nitride MEMS contour-mode resonator," J. Semicond., vol. 37, no. 10, 101001, 2016.

https://doi.org/10.1088/1674-4926/37/10/101001.

4. J. Zou, C. S. Lam, "Electrode design of AIN Lamb wave resonators," in 2016 IEEE International Frequency Control Symposium (IFCS) Proceedings, 2016, pp. 1-5.

https://doi.org/10.1109/FCS.2016.7563573.

5. V. Pashchenko, R. Matloub, F. Parsapourkolour, P. Muralt, S. Ballandras, K. Haffner, "Hybrid BAW/ SAW AIN and AISCN thin film resonator," in 2016 IEEE International Ultrasonics Symposium (IUS) Proceedings, pp. 1-4, 2016.

https://doi.org/10.1109/ULTSYM.2016.7728649

6. C. Tu, J. Lee, "VHF-band biconvex AIN-on-silicon micromechanical resonators with enhanced quality factor and suppressed spurious modes," J. Micromech. Microeng., vol. 26, no. 6, 065012, 2016. https://doi.org/10.1088/0960-1317/26/6/065012/

7. G. Chen, C. Cassella, Z. Qian, G. E. Hummel, M. Rinaldi, "Lithographically defined aluminium nitride cross-sectional Lamé mode resonators," J. Micromech. Microeng., vol. 2, no. 3, 034003, 2017. https://doi.org/10.1088/1361-6439/aa5a83.

8. M. Wei, A. Avila, I. Rivera, M. Baghelani, J. Wang, "ZnO on nickel RF micromechanical resonators for monolithic wireless communication applications," J. Micromech. Microeng., vol. 27, no. 5, 05506, 2017.

https://doi.org/10.1088/1361-6439/aa635c.

9. A. Frangi, M. Cremonesi, A. Jaakkola, T. Pensala, "Analysis of anchor and interface losses in piezoelectric MEMS resonators," Sens. Actuators, A, vol. 190, pp. 127-135, 2013. https://doi.org/10.1016/j.sna.2012.10.022

10. S. Ghaffari, S. A. Chandorkar, S. Wang, E. J. Ng, C. H. Ahn, V. Hong, Y. Yang, T. W. Kenny, "Quantum
Limit of Quality Factor in Silicon Micro and Nano Mechanical Resonators," Scientific Reports, vol. 3, 3244, 2013. https://doi.org/10.1038/srep03244.

11. J. Segovia-Fernandez, M. Cremonesi, C. Cassella, A. Frangi, G. Piazza, "Anchor Losses in AIN Contour Mode Resonators," J. Microelectromech. Syst., vol. 24, no. 2, pp. 265-275, 2015. https://doi.org/10.1109/JMEMS.2014.2367418.

12. N. K. Kuo et al., "Micromachined sapphire $\mathrm{GHz}$ lateral overtone bulk acoustic resonators transduced by aluminum nitride," in 2012 IEEE 25th International Conference on Micro Electro Mechanical Systems (MEMS) Proceedings, 2012, pp. 27-30. https://doi.org/10.1109/MEMSYS.2012.6170085.

13. S. Gong, N.-K. Kuo, G. Piazza, "A 1.75 GHz piezoelectrically-transduced SiC lateral overmoded bulk acoustic-wave resonator," in 16th International Solid-State Sensors, Actuators and Microsystems Conference TRANSDUCERS'11 Proceedings, 2011, pp. 922-925.

https://doi.org/10.1109/TRANSDUCERS.2011.5969701.

14. L. W. Hung, C. T. C. Nguyen, "Capacitive-piezoelectric AIN resonators with Q>12,000," in 2011 IEEE 24th International Conference on Micro Electro Mechanical Systems Proceedings, Cancun, 2011, pp. 173-176. https://doi.org/10.1109/MEMSYS.2011.5734389

15. J.Zou, "High quality factor Lamb wave resonators," EECS Department University of California, Berkeley Technical Report No. UCB/EECS-2014-217, December 15, 2014. [Online]. Available: https:// www2.eecs.berkeley.edu/Pubs/TechRpts/2014/ EECS-2014-217.html. [Accessed: 28-Sep-2019].

16. L. Popa, D. Weinstein, "Switchable piezoelectric transduction in AIGaN/GaN MEMS resonators," in 2013 Transducers \& Eurosensors XXVII: The 17th International Conference on Solid-State Sensors, Actuators and Microsystems Proceedings, 2013, pp. 2461-2464.

17. G. Piazza, P. J. Stephanou, A. P. Pisano, "One and Two Port Piezoelectric Higher Order ContourMode MEMS Resonators for Mechanical Signal Processing," vol. 51, no. 11-12, pp.1596-1608, 2007.

https://doi.org/10.1016/j.sse.2007.09.037

18. S. Gong, N.-K. Kuo, G. Piazza, "GHz AIN lateral overmoded bulk acoustic wave resonators with a $\mathrm{f} \cdot \mathrm{Q}$ of $1.17 \times 10^{13}$, , in 2011 Joint Conference of the IEEE International Frequency Control Symposium and European Frequency and Time Forum Proceedings, 2011, pp. 1-5. https://doi.org/10.1109/FCS.2011.5977846.

19. C. Tu, J. E.-Y. Lee, "A semi-analytical modeling approach for laterally-vibrating thin-film piezoelec- 
tric-on-silicon micromechanical resonators," J. Micromech. Microeng., vol. 25, no. 11, 115020. https://doi.org/10.1088/0960-1317/25/11/115020.

20. C. Zuo, J. V. Der Spiegel, G. Piazza, "1.05-GHz CMOS oscillator based on lateral- field-excited piezoelectric AIN contour- mode MEMS resonators," in IEEE Transactions on Ultrasonics, Ferroelectrics, and Frequency Control Proceedings, vol. 57, no. 1, 2010, pp. 82-87. https://doi.org/10.1109/TUFFC.1382.

21. M. Rinaldi, C. Zuniga, G. Piazza, "5-10 GHz AIN Contour-Mode Nanoelectromechanical Resonators," in 2009 IEEE 22nd International Conference on Micro Electro Mechanical Systems Proceedings, 2009, pp. 916-919. https://doi.org/10.1109/MEMSYS.2009.4805533.

22. R. Lu, Y. Yang, S. Link and S. Gong, "Enabling Higher Order Lamb Wave Acoustic Devices With Complementarily Oriented Piezoelectric Thin Films," in Journal of Microelectromechanical Systems, https://doi.org/10.1109/JMEMS.2020.3007590.

23. Chen, Guofeng and Matteo Rinaldi. "High-Q X Band Aluminum Nitride Combined Overtone Resonators." 2019 Joint Conference of the IEEE International Frequency Control Symposium and European Frequency and Time Forum (EFTF/IFC) (2019): 1-3

24. A. V. Nasedkin, "Some finite element methods and algorithms for solving acousto-piezoelectric problems," in Piezoceramic materials and devices, I. A. Parinov., Ed. New York: NovaScience Publishers, 2010, pp. 177-218.
25. V. Akopyan, A. Solov'ev, I. Parinov, S. Shevtsov, Definition of constants for piezoceramic materials, 1st ed. New York, 2010.

26. J. Zou, C.-M. Lin, C. S. Lam, A. P. Pisano, "Transducer design for AIN Lamb wave resonators," J. Appl. Phys., vol. 121, no. 15, 154502, 2017.

https://doi.org/10.1063/1.4979914.

27. M. Rais-Zadeh et al., "Gallium Nitride as an Electromechanical Material," J. Microelectromech. Syst., vol. 23, no. 6, pp. 1252-1271, 2014. https://doi.org/10.1109/JMEMS.2014.2352617

28. M. Yu. Dvoesherstov, V. I. Cherednik, S. I. Bosov, I. Ya. Orlov, O. V. Rudenko, "Numerical and experimental analysis of the parameters of an electroacoustic thin-film microwave resonator," Acoust. Phys., vol. 59, no. 5, pp. 513-520, 2013. https://doi.org/10.1134/S1063771013050072.

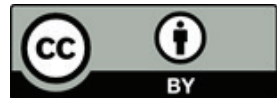

Copyright $\odot 2020$ by the Authors. This is an open access article distributed under the Creative Commons Attribution (CC BY) License (https://creativecommons.org/licenses/by/4.0/), which permits unrestricted use, distribution, and reproduction in any medium, provided the original work is properly cited.

Arrived: 06. 11. 2020

Accepted: 08. 09. 2020 